\title{
THE PECILARITIES OF THE INDEPENDENCE OF THE PRIMARY SCHOOL CHILDREN IN THE CONDITIONS OF DISTANCE EDUCATION
}

\author{
Hakobyan S., Khanamiryan I. (Yerevan State University, Yerevan, Armenia) \\ sonahakobyan97@mail.ru,irina.khanamiryan@gmail.com
}

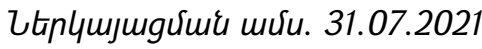

9pmpunuर्ume uर्जu. 27.08.2021

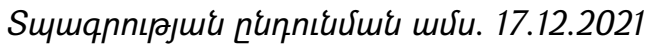

\begin{abstract}
This article reflects the concepts of teachers and parents about the independence of primary schoolchildren in the context of the 2020 pandemic. A comparative analysis is given between the characteristics and types of independence (activity, criticality and flexibility of thinking, independent homework, dependence on parents when performing various tasks, etc.) in the conditions of distance and full-time education. Independence is especially important at primary school age, when educational activity becomes dominant. The study is aimed at studying the characteristics of the independence of primary schoolchildren, for whom the transition to distance learning has become especially critical, given their age characteristics. According to the hypothesis, it is assumed that, in contrast to full-time education, distance learning contributes to the development of the independence of primary school children. An expert survey was conducted using 2 questionnaires. The research results are presented in the form of corresponding conclusions. In general, it can be stated that distance learning negatively affects the activity, self-confidence and independence of primary school children.
\end{abstract}

Keywords: independence, activity, educational process, distance learning.

DOI: https://doi.org/10.46991/SBMP/2022.5.1.040

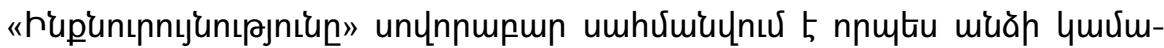

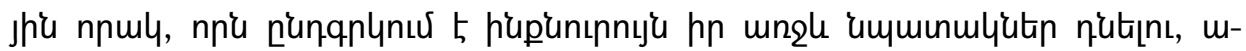

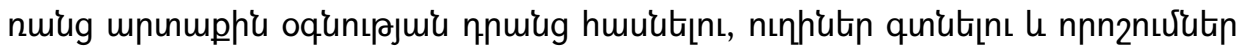

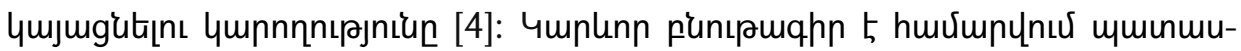

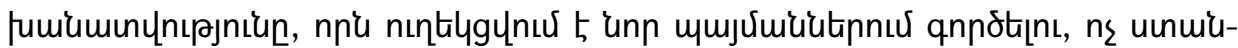

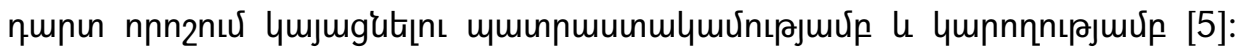

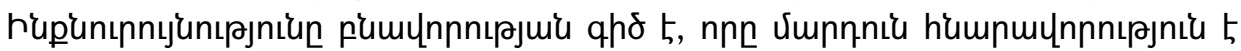

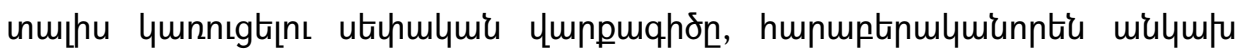

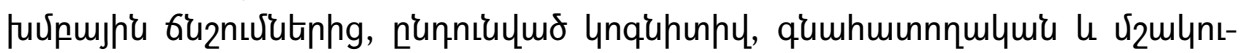

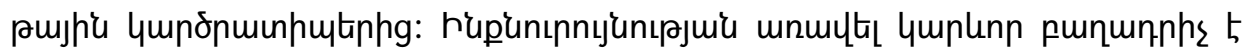




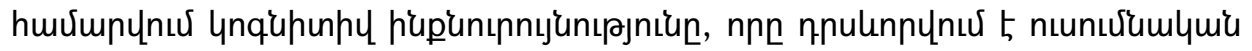

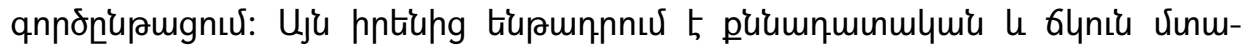

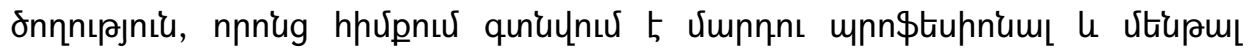
4umnnnıpjniuutitn [3]:

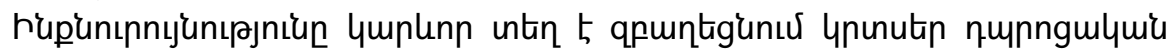

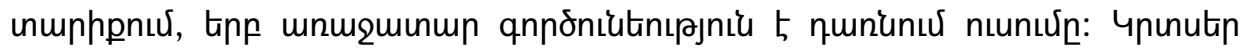

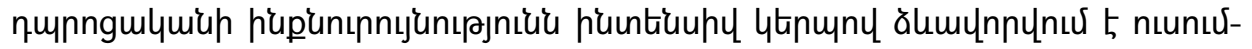

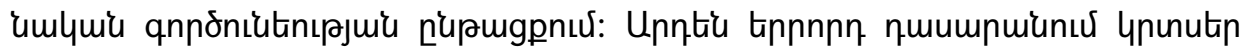

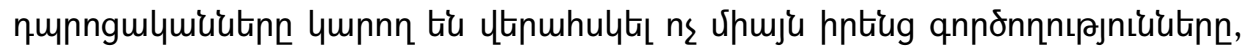

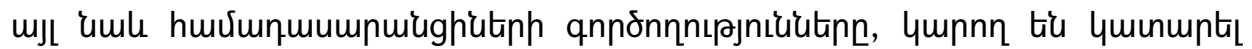

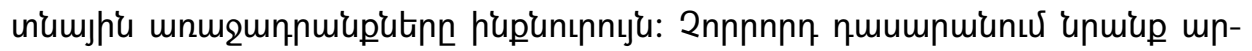

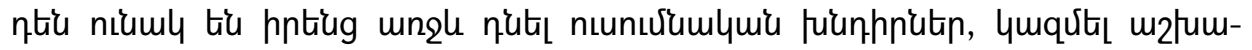

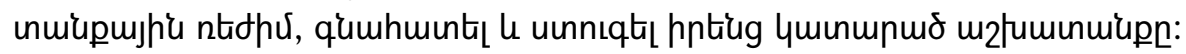

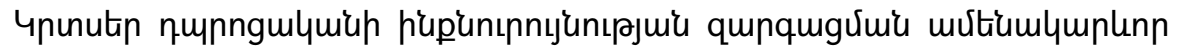

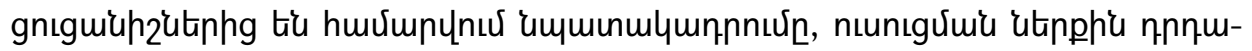

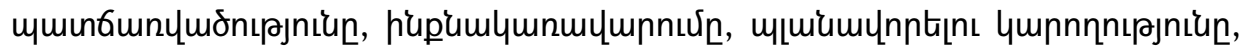

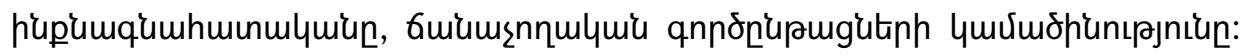

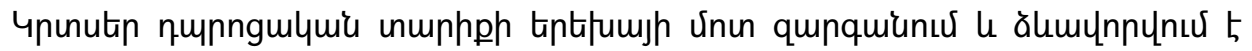

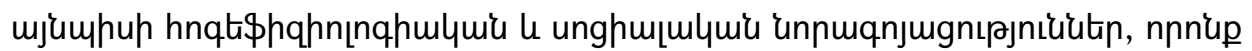

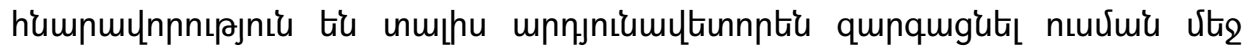

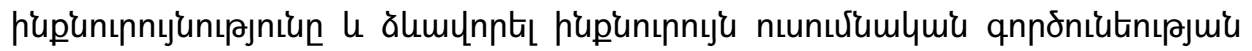

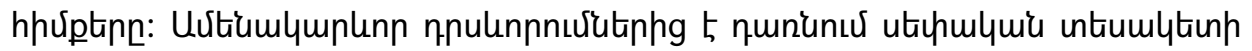

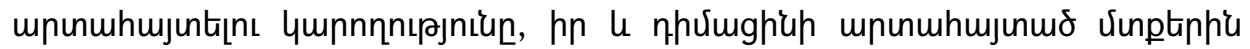

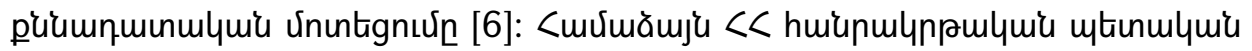

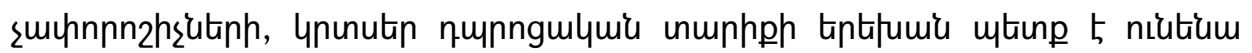

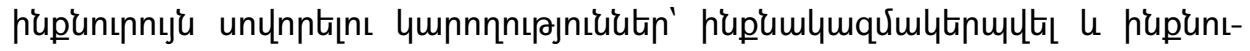

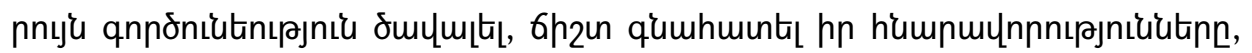

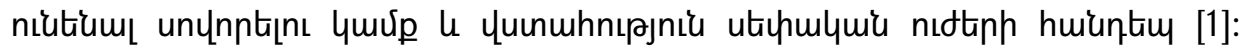

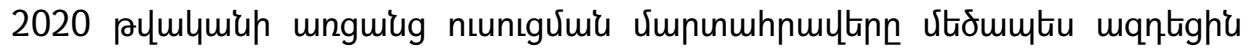

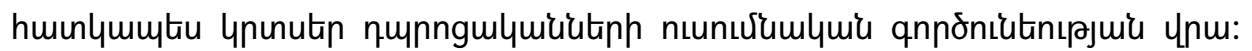

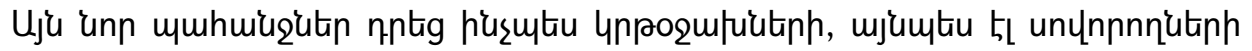
ungle:

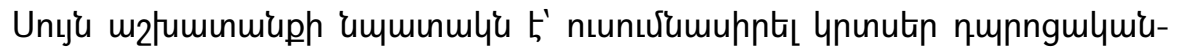

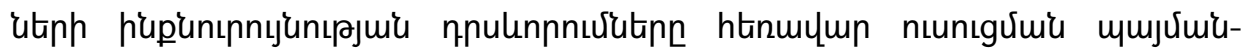
utipnus:

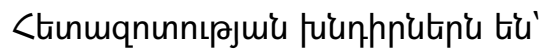

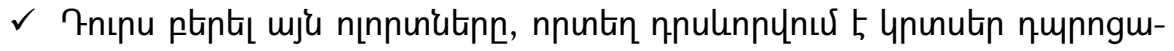

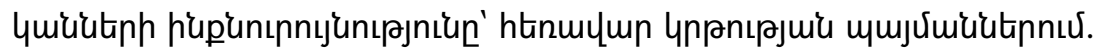

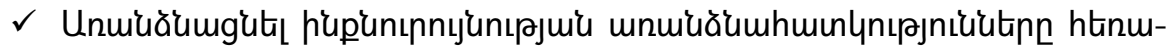

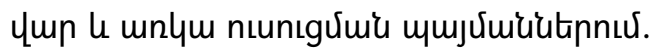




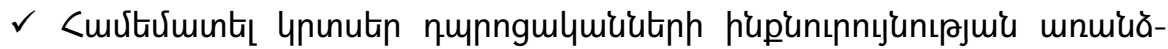

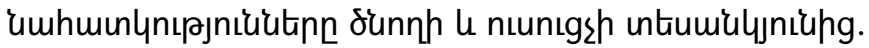

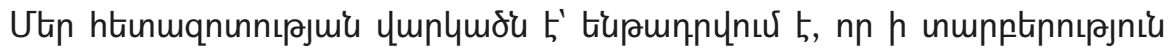

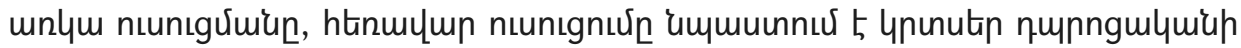

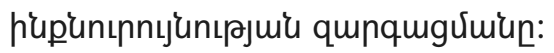

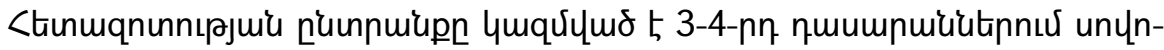

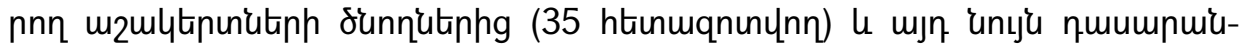

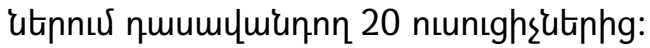

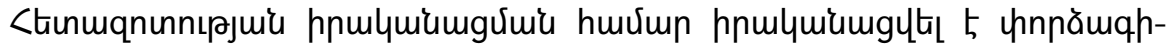

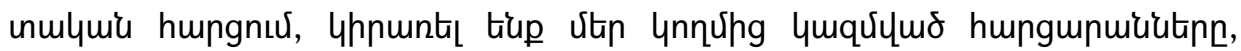

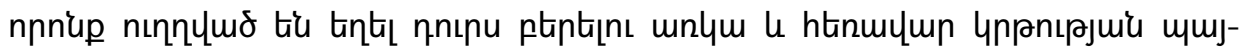

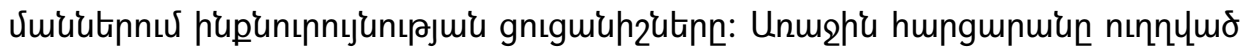

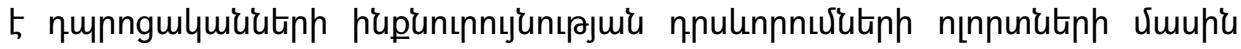

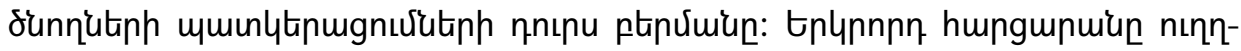

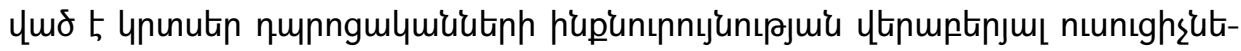

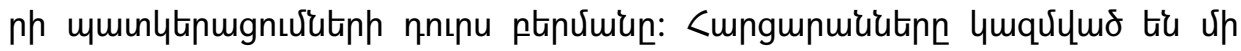

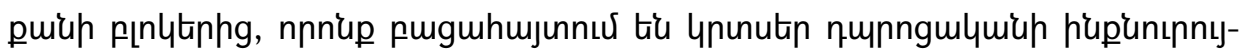

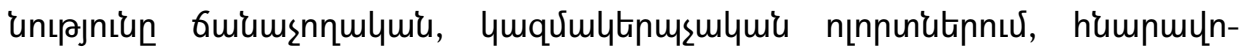

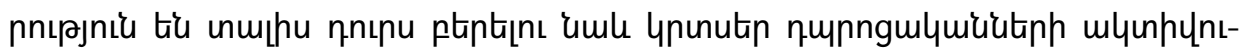

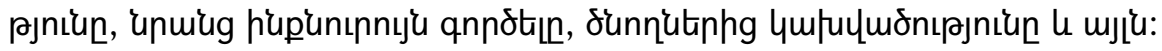

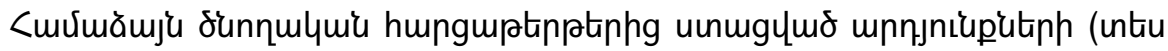

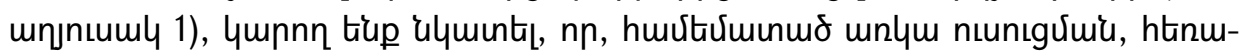

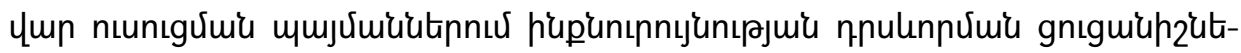

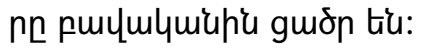

Unjniuml 1.

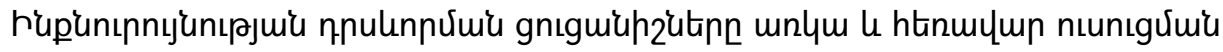

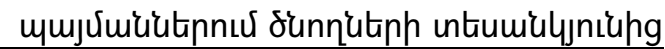

\begin{tabular}{|c|c|c|}
\hline & Unlum & Ctrnulump \\
\hline 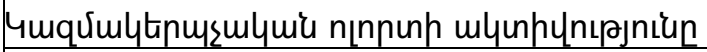 & $70,6 \%$ & $29,4 \%$ \\
\hline 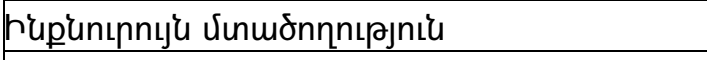 & $76,5 \%$ & $23,5 \%$ \\
\hline Cunhwiunın muınhцnıрлnı̌ & $76,4 \%$ & $23,6 \%$ \\
\hline 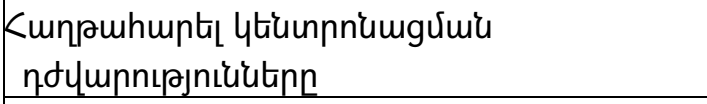 & $73,5 \%$ & $26,5 \%$ \\
\hline 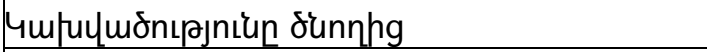 & $32,4 \%$ & $67,6 \%$ \\
\hline Uuunwhnıpjniu utıhulymü nıdtiphu & $69,6 \%$ & $30,4 \%$ \\
\hline
\end{tabular}

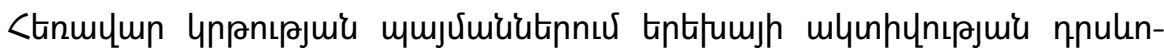

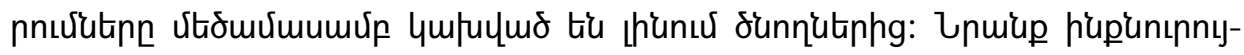

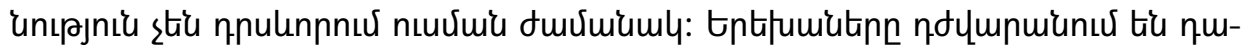

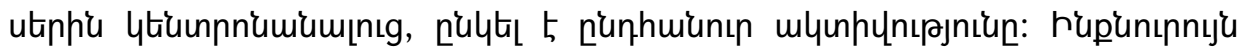




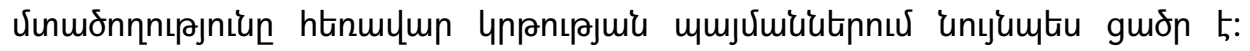

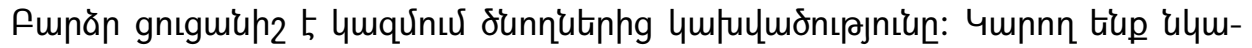

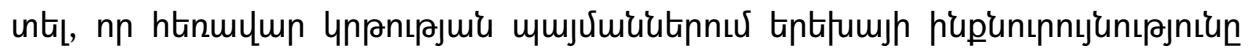

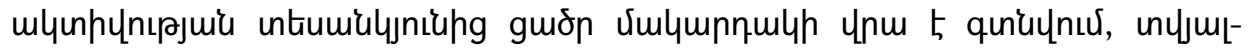

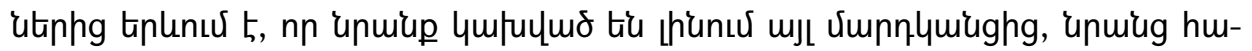

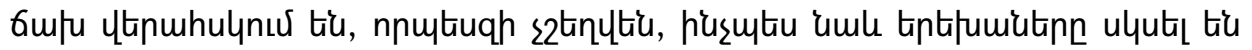

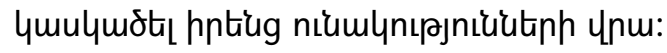

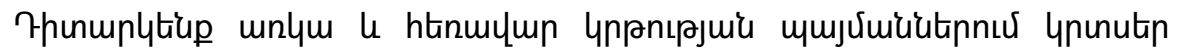

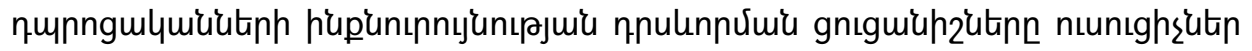
untumilyjniung:

Unjniuml 2.

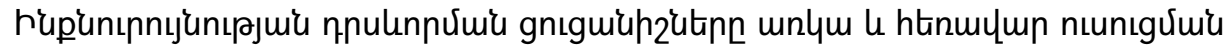

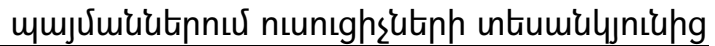

\begin{tabular}{|c|c|c|c|}
\hline & Unlum & Ktnuulun & 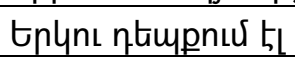 \\
\hline 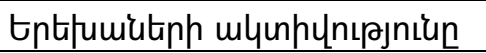 & $90,9 \%$ & $9,1 \%$ & - \\
\hline 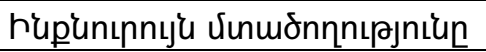 & $72,8 \%$ & $18,2 \%$ & $9,1 \%$ \\
\hline 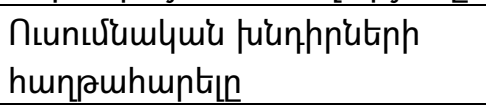 & $54,5 \%$ & $9,1 \%$ & $36,1 \%$ \\
\hline 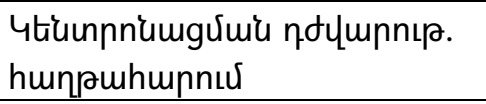 & $72,7 \%$ & - & $18,2 \%$ \\
\hline Lupuunulyunnnuर्u & $54,5 \%$ & - & $45,5 \%$ \\
\hline Stumbliunh mpunuhmjunnuv & $36,4 \%$ & - & $45,5 \%$ \\
\hline 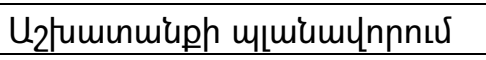 & $45,5 \%$ & - & $54,5 \%$ \\
\hline
\end{tabular}

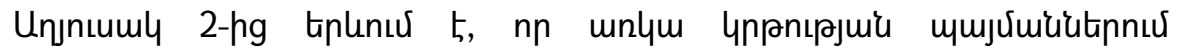

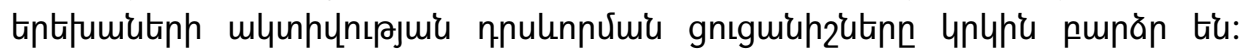

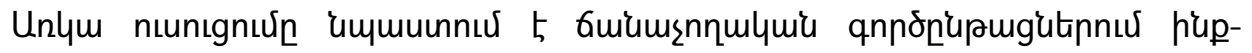

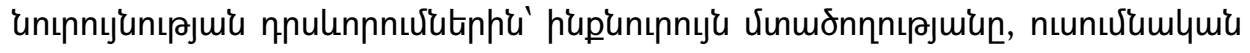

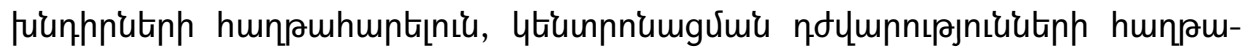

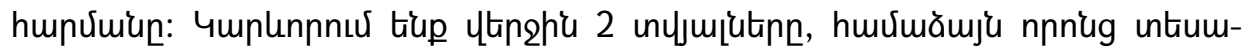

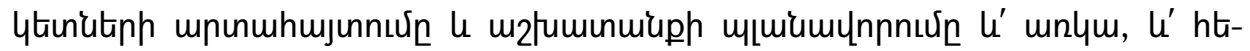

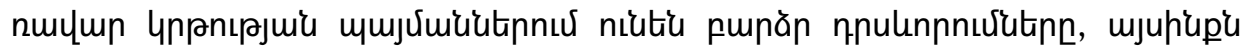

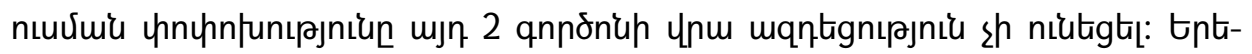

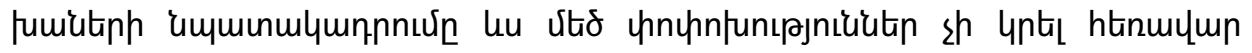

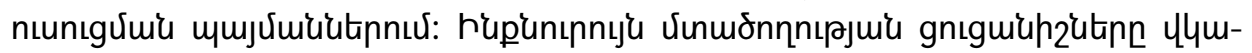

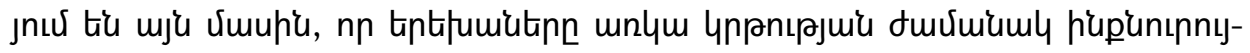

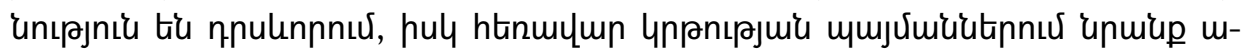

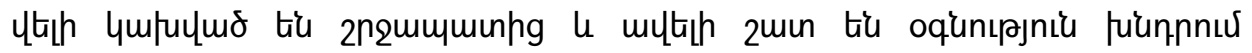
dunnutunng: 


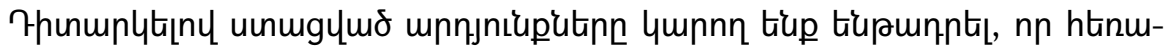

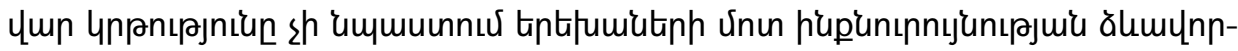

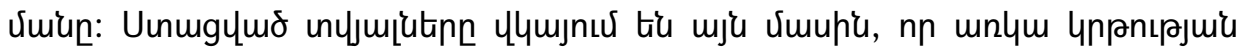

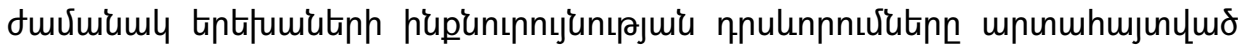

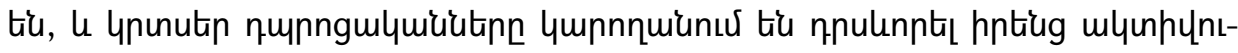
pjniǔ unumptip nınnunutinnuर:

\section{tqnulqugnıpjnilutin}

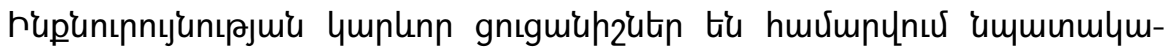

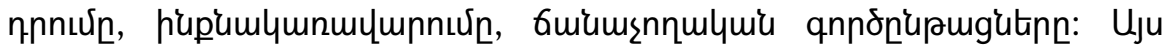

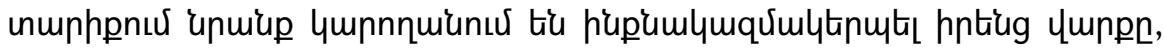

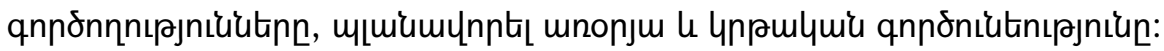

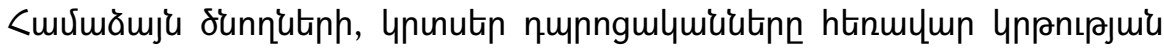

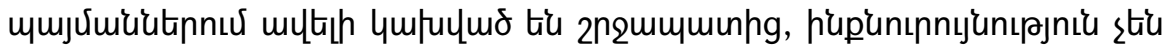

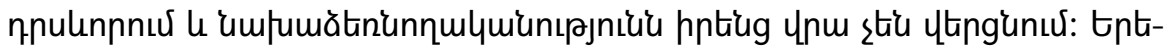

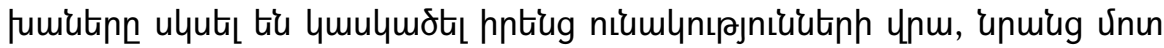

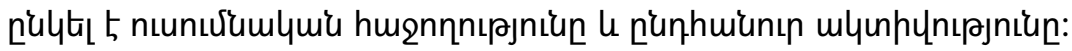

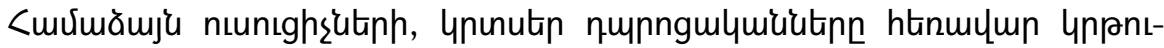

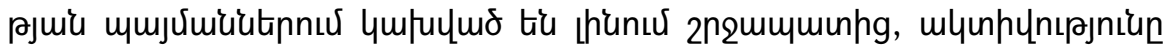

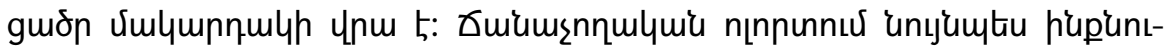

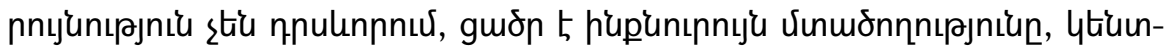

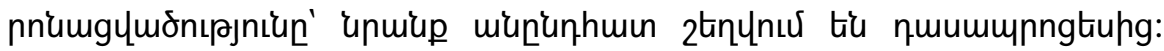

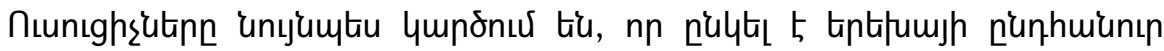
mlynhynıpjniun:

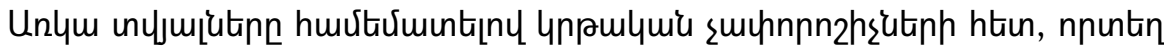

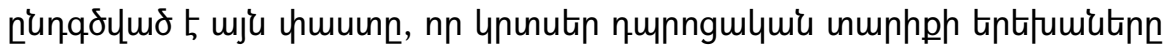

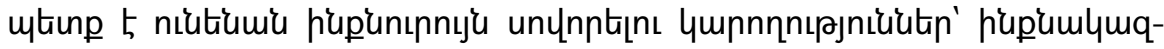

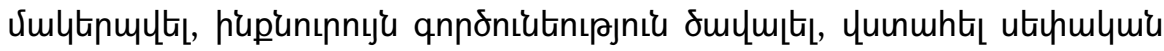

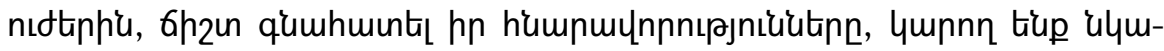

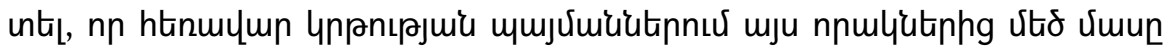
pugulqujnuर 5 :

\section{9pulquínıpjnit}

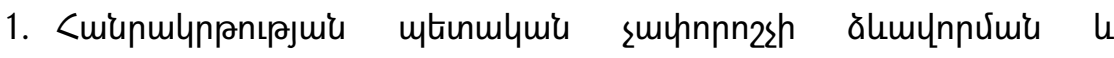
huuunuinuluib yunq:

https://www.arlis.am/DocumentView.aspx?DoclD=77183

2. Абрамова Г. С. А 16 Возрастная психология: Учеб. пособие для студ. Вузов., 4-е изд., стереотип. - М.: Издательский центр «Академия», 1999.-672 с. ISBN 5-7695-0303-3

3. Баранов Е.Г. Формирование самостоятельности личности.// Ежегодник Российского психологического общества: Материалы 
3-го Всероссийского съезда психологов.25-28 июня 2003 года:Т.1. - СПб.: Изд-во С.-Петерб. ун-та,2003. - с. 289-293

4. Корсини Р. А. Ауэрбаха, Психологическая энциклопедия /Под ред - СПб., 2006, с. 424.

5. Психолого-педагогический словарь для учителей и руководителей общеобразовательных учреждений. - Р.н/Д.:Феникс, 1998. - 544с.

6. Савельева Т.М. Самостоятельность младшего школьника и показатели еe развития / Т.М. Савельева// Пачатковаенавучанне. - 2012, №6., с. 28-31.

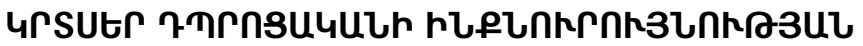

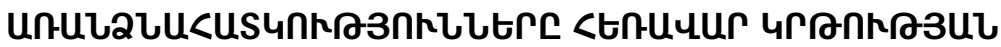 TusuUuttrniv}

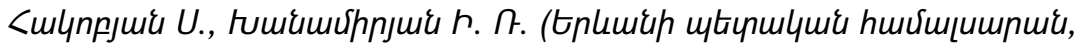
tрlиши, <щјмичми)

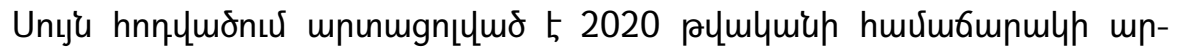

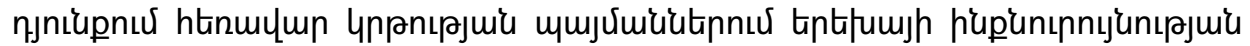

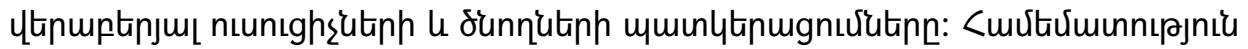

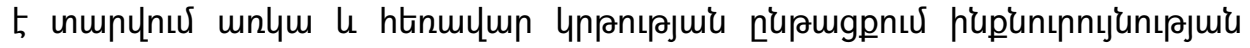

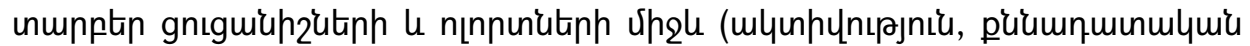

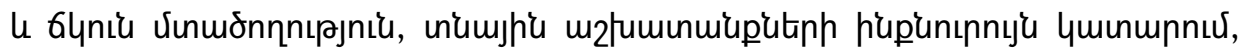

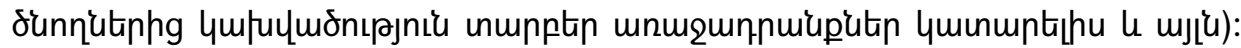

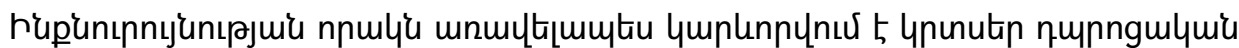

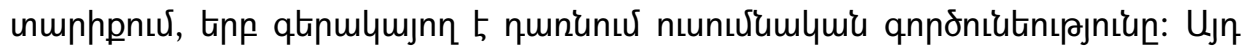

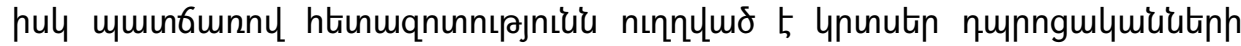

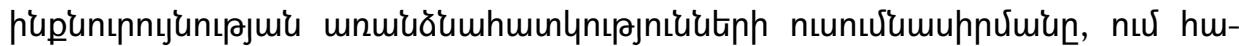

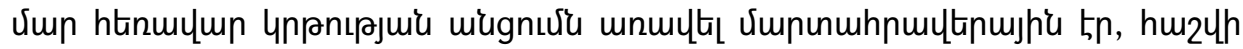

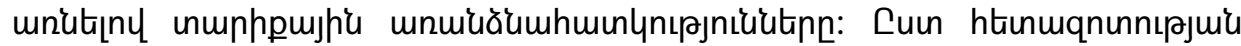

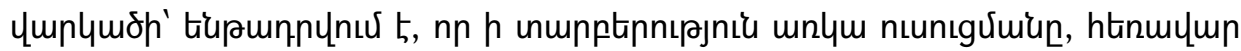

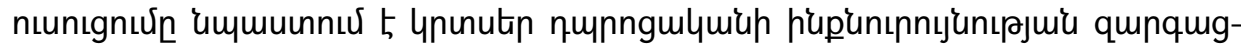

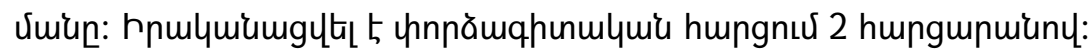

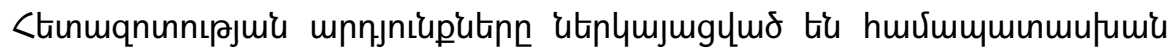

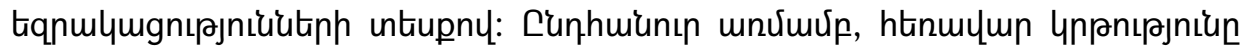

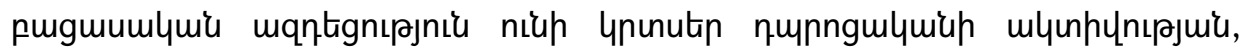

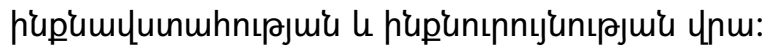

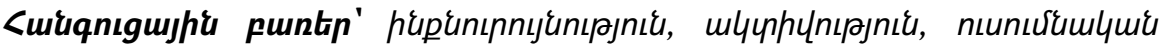

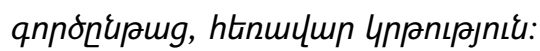




\section{ОСОБЕННОСТИ САМОСТОЯТЕЛЬНОСТИ МЛАДШИХ ШКОЛЬНИКОВ В УСЛОВИЯХ ДИСТАНЦИОННОГО ОБУЧЕНИЯ}

Акопян С., Ханамирян И. (Ереванский государственный университет, Ереван, Армения)

В данной статье отражены представления учителей и родителей о самостоятельности младших школьников в условиях пандемии 2020 года. Дается сравнительный анализ между особенностями и видами самостоятельности (активность, критичность и гибкость мышления, самостоятельное выполнение домашнего задания, зависимость от родителей при выполнении различных заданий и др.) в условиях дистанционного и очного обучения. Самостоятельность особенно важна в младшем школьном возрасте, когда доминантой становится учебная деятельность. Исследование направлено на изучение особенностей самостоятельности младших школьников, для которых переход на дистанционное обучение стало особенно критичным, учитывая их возрастные особенности. Согласно гипотезе предполагается, что в отличие от очного образования дистанционное обучение способствует развитию самостоятельности младших школьников. Был проведен экспертный опрос по 2 анкетам.

Результаты исследования представлены в виде соответствующих выводов. В целом можно констатировать, дистанционное обучение негативно сказывается на активности, уверенности в себе и самостоятельности младших школьников.

Ключевые слова: самостоятельность, деятельность, образовательный процесс, дистанционное обучение. 